Journal of Agricultural Sciences
(Tarim Bilimleri Dergisi)

\title{
Investigating the Effect of Long-Term Sugarcane Cultivation on Some Soil Properties of Soils in Karoun Agro-industry Unit, Khuzestan Province, Iran
}

\author{
Masoud Sadeghi MIANROODI ${ }^{\text {a,c }}(\mathbb{D})$, Abdolamir MOEZZI ${ }^{b} \mathbb{D}^{\mathbb{D}}$, Ali GHOLAMI $^{\mathrm{c}^{*}}(\mathbb{D}$, \\ Teimour BABAEI NEJAD ${ }^{c}$ D , Ebrahim PANAHPOUR ${ }^{c}$ iD \\ ${ }^{a}$ Department of Soil Science, Khuzestan Science and Research Branch, Islamic Azad University, Ahvaz, IRAN \\ ${ }^{b}$ Department of Soil Science, Faculty of Agriculture, Shahid Chamran University of Ahvaz, Ahvaz, IRAN \\ ${ }^{c}$ Department of Soil Science, Ahvaz Branch, Islamic Azad University, Ahvaz, IRAN
}

ARTICLE INFO

Research Article

Corresponding Author: Ali GHOLAMI, E-mail: ali.gholami54@gmail.com

Received: 27 May 2019 / Revised: 31 August 2019 / Accepted: 16 September 2019 / Online: 18 January 2021

\section{ABSTRACT}

The principal aim of the present research was investigation of the effect of long-term sugarcane cultivation on some chemical and physical properties of soil in Karoun Agro-industry Unit in Shoushtar city, Iran. The study was conducted in a factorial arrangement based on randomized complete block design with two field factors at 8 levels and three depths in three replications. Soil samples were collected and some of their physical (e.g., bulk density) and chemical (e.g., pH, EC, soil available phosphorus, organic carbon, soluble sodium and available potassium)
Features9 were measured. Results revealed that land use change and longterm sugarcane cultivation reduced electrical conductivity, the amount of soluble sodium and available potassium contents of soil in different depths, while caused increasing the percentage of organic matter and available soil phosphorous. However, at similar experimental conditions, no significant changes were observed in soil $\mathrm{pH}$. The soil bulk density contents in farms under continuous cultivation of sugarcane, was more than the control field and HARZA. Moreover, soil exchangeable potassium was identified as a sensitive indicator of long-term sugarcane cultivation.

Keywords: Calcium carbonate, Cultivation, Electrical conductivity, Organic carbon, Soluble sodium, Sugarcane

\section{Introduction}

(C) Ankara University, Faculty of Agriculture

Compact cropping and lack of suitable management approaches in agricultural fields all over the world have affected soil properties in vast areas and led to changes in soil quality. Cultivation of sugarcane (Sacchrum officinarum L.) was mechanized in the southwest of Iran in the late 1950s. Over the past 40 years, the sugarcane yield has been declined from 110 to 50 tons per hectare over the same period of time. The use of heavy machinery during planting, harvesting and transportation operations in soils with good texture leads to concern that soil compaction may reduce the productivity in the long term (Barzegar et al. 2005).

One of the most appropriate methods for evaluation of the quality of soil is studying the changes in soil properties through continuous use and analysis of the results. Selection of key indicators of soil quality is effective in evaluating these changes and determining the improvement, stability, or degradation of soil quality (Bünemann et al. 2018). Destruction of physical and chemical properties of soils is one of the most important problems in agro-industrial units. Despite the annual addition of chemical fertilizers, sugarcane crop yields have been declined. Naranjo et al. (2006) investigated the effect of 30 years of sugarcane cultivation on soils properties and they found that continuous cultivation reduced soil organic matter (SOM) and compacted the soils.

In the study in Ethiopia on the effects of 50 years of sugarcane cultivation on some of the physical and chemical properties of soil, Dengia and Lantinga (2016) found that SOM levels were 53 and 34\% lower than other areas with depths of 0-30 and 30$60 \mathrm{~cm}$, respectively. However, other factors such as $\mathrm{pH}$ and electrical conductivity (EC) of the soil were not significantly affected by long-term cropping, compared to the control land. Perhaps one of the possible causes of this decline is soil degradation. Therefore, the main soil quality indices are evaluated for the extent of changes that may be made with regard to the application of conventional long-term crops. The long-term cultivation period ( 6 to 7 months), high water consumption ( 30,000 cubic meters per hectare at 25 to 30 turns irrigation), and extensive use of heavy machinery in the planting stage and sugarcane harvesting, 
may change soil properties. In order to determine how these changes are taking place, it is necessary to examine the land qualitatively and quantitatively in order to prevent further destruction of this vast God-given source. Due to the fact that few researches have so far been conducted on the long-term effects of cultivation on the physical and chemical properties of soil, this study aimed to investigate the effect of sugarcane mechanized cultivation in a 40-year period on some of soil characteristics in Karoon Agro-industry.

\section{Material and Methods}

\subsection{Study area}

This research was carried out to investigate the effect of long-term sugarcane cultivation on soil chemical and physical properties in Karoun Agro-industry Unit in Dimcheh with the geographical coordinates Latitude: $32^{\circ} 02^{\prime} 60.00^{\prime \prime} \mathrm{N}$ Longitude: 48 $50^{\prime}$ 59.99" E and 68 meters above mean sea level located at 12 kilometers to the west of Shoushtar, city in Khuzestan province, Iran (Figure 1). The total area of the land is 45,000 hectares (Moradi et al. 2014). This area has warm and dry climate conditions. The dominant soils of the area are classified in the large Calcic Haplousteps group (Staff 2014).

\section{Karoun Agro-industry}

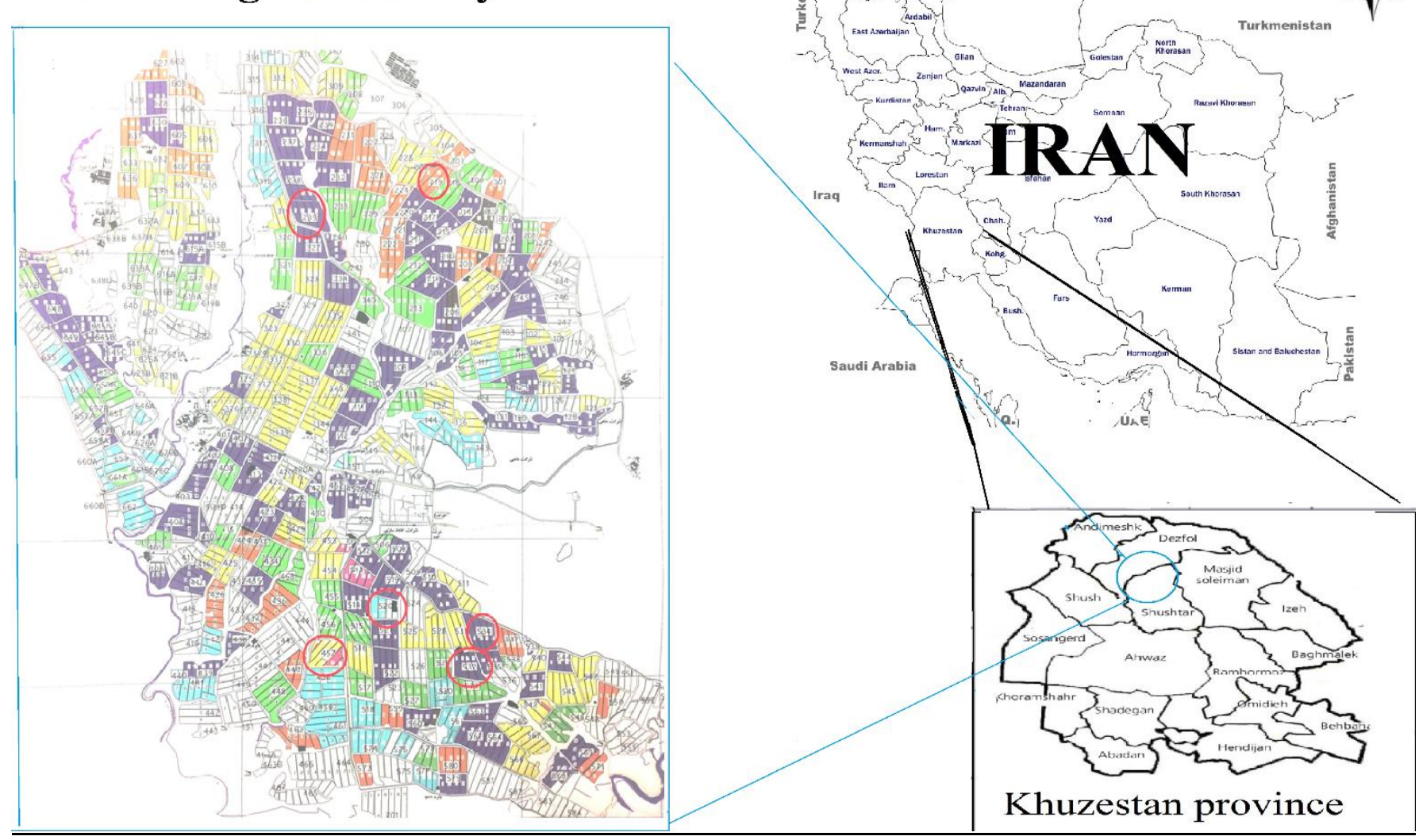

Figure 1- Location of the area under study in Khuzestan province

\subsection{Analytical chemistry}

The measured soil characteristics are included $\mathrm{pH}$, electrical conductivity (EC) of saturation extract, soil available phosphorus measured by extraction with sodium bicarbonate, organic carbon obtained via wet oxidation method using potassium dichromate and concentrated sulfuric acid, soluble sodium of soil saturation extract and soil available potassium (extracted via ammonium acetate) using flame photometer, and the bulk density in soils. Data analysis was carried out as a factorial experiment in a randomized complete block design with two factors, farms in 8 levels including 6 farms numbered 219, 239, 457, 520, 532, 534, Harza report and control field, with soil depth treatment in three levels of depth including 0-30, 30-60, 90-60 cm in three replications.

\subsection{Statistical analysis}

Statistical analysis of data was performed by SAS 9.2 software and the comparison of means was made using Duncan's multidomain test at $1 \%$ probability level. Figures were also drawn using Microsoft Excel software. 


\section{Results and Discussion}

\subsection{Electrical conductivity and $\mathrm{pH}$ of soil}

The results showed that continuous cultivation of farms resulted in a statistically significant reduction in EC levels. The average EC in the surface horizon $(0-30 \mathrm{~cm})$ was decreased from $17.8 \mathrm{dS} \mathrm{m}^{-1}$ in uncultivated land to $0.85 \mathrm{dS} \mathrm{m}^{-1}$ in sugarcane-cultivated fields. By comparing the EC of the HARZA report and the sugarcane cultivated fields, no statistically significant difference was observed among them, indicating that the drainage and initial discharge of the farms at the early stages of Karoun Agro-industry Unit had reduced EC in soil via losing the salts (Figure 2). Studies of Landi et al. (2018) implied that land use change and longterm cultivation of sugarcane in northwest of Iran in both studies caused a significant decrease in soil EC. The results of the comparison between the Duncan's means showed that there is no significant difference between the pH of soils in the cultivated fields, control treatment, and Harza report. The average of soil $\mathrm{pH}$ in the $0-30 \mathrm{~cm}$ horizon of soil was found to be 7.7 in the control treatment and 8.05 in sugarcane cultivated farms. A similar trend was observed at depths 30-60 and 60-90 cm (Figure 3). Dengia and Lantinga (2016) stated that $\mathrm{pH}$ values of pristine land and cultivated land were not significantly different.

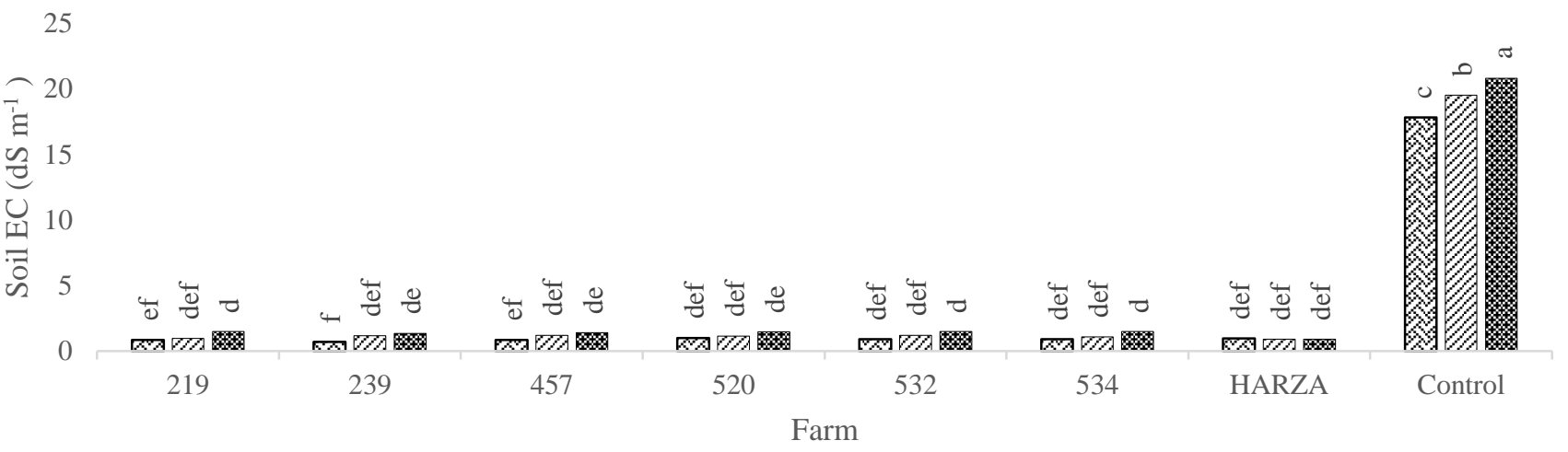

Figure 2- Comparison of means of electrical conductivity in farms under sugarcane and control and Harza report

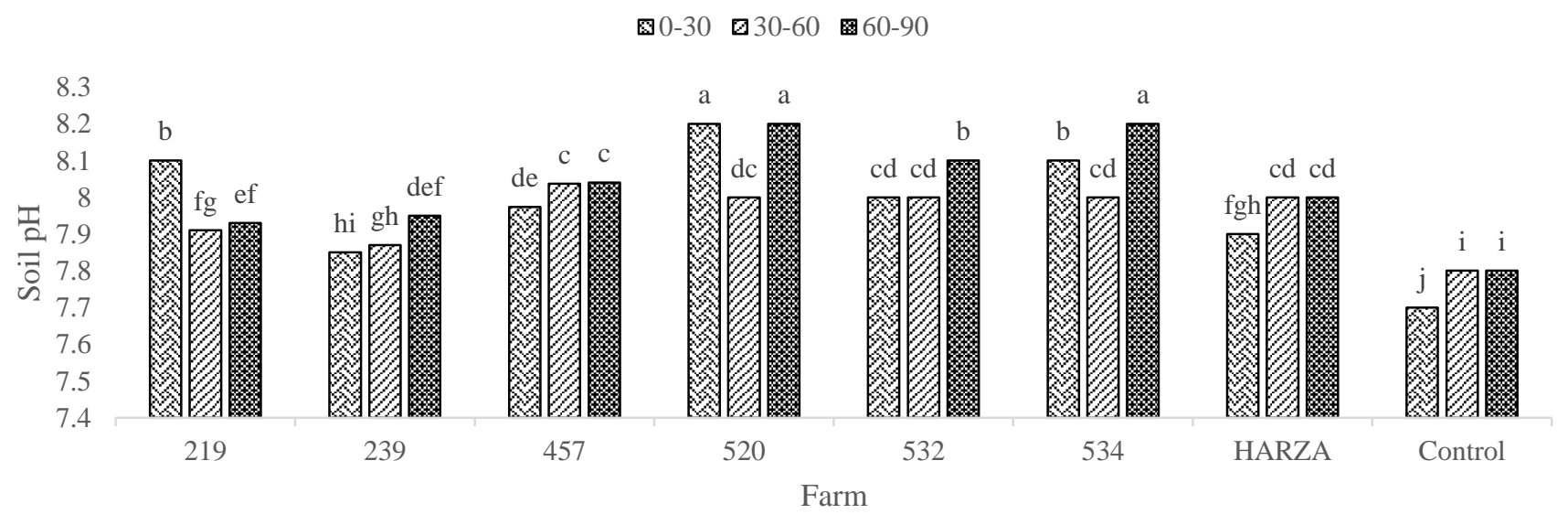

Figure 3- Comparison of means of $\mathrm{pH}$ in sugarcane cultivated soil and that of control and Harza report

\subsection{Soil organic matter}

The soil organic matter ( $\mathrm{SOM}$ ) values in soils under sugarcane at $0-30 \mathrm{~cm}$ of depth was significantly higher than that of soils in the control and HARZA farms: the SOM average at depths of $0-30 \mathrm{~cm}$ in the soils under sugarcane, the HARZA soil and the control soil were $1.45,0.6$ and $0.65 \%$, respectively (Figure 4 ). It is obvious that the main reasons for SOM increase are cultivation practices which applied in the farms. The content of SOM was higher in lower depths of soil under sugarcane cultivation as compared with the adjacent pristine soils: the means of SOM in the 30-60 and 60-90 cm horizons in the cultivated soil were 0.62 and $0.41 \%$, respectively. These contents were 0.33 and $0.42 \%$ in HARZA and control, respectively. This is probably due to sugarcane deep roots and its high production of biomass. 
The presence of sugarcane roots and root discharges in different stages of growth can increase the SOM content of soils under sugarcane cultivation (Amerikhah et al. 2010). Silva et al. (2007) also found that long-term sugarcane cultivation in Brazil increased SOM. A decrease of SOM at deeper levels has been reported by many researchers, resulting from reduced root density (Blanco-Canqui and Lal 2007). Generally, due to the lack of SOM in pristine soils in arid and semi-arid areas, cultivation and irrigation can increase SOM content in such lands (Jafari et al. 2016).

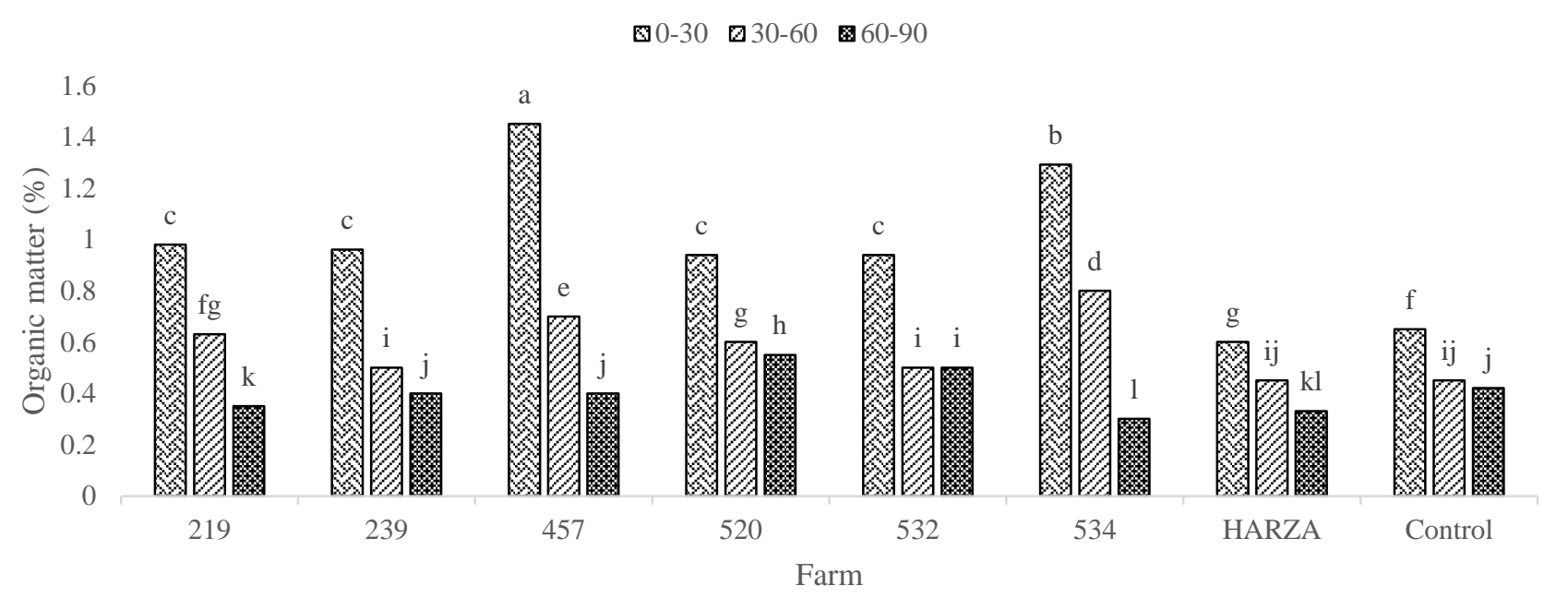

Figure 4- Comparison of means of SOM in sugarcane cultivated soil and that of control and Harza report

\subsection{Soluble sodium}

As can be seen in the results of the analysis of variance of soluble sodium in soils in different farms, there was a significant difference at the probability level of $1 \%$ error, but there was no significant difference resulting from the sampling depth (Table 1). Regarding the results of mean comparison, it was observed that the soluble sodium content of soil was not significantly different in the studied farms, but this difference was significant in comparison with the soil in the control and HARZA report (Figure 5). It seems that the pristine lands in studied lands are mostly very salty whose predominant salt, is mainly sodium chloride. Prior to cultivating sugarcane in the studied area, initial leaching has been conducted, leading to the loss of additional salts such as sodium, and continuous cultivation of sugarcane and heavy irrigation operations on these fields has also resulted in the leaching of soluble sodium through the drainage. In agreement with present study, the conversion of virgin land to sugar beet cultivation investigation showed that the soluble sodium content was reduced in the cultivated soil compared with the adjacent virgin lands (Rezapour et al. 2013).

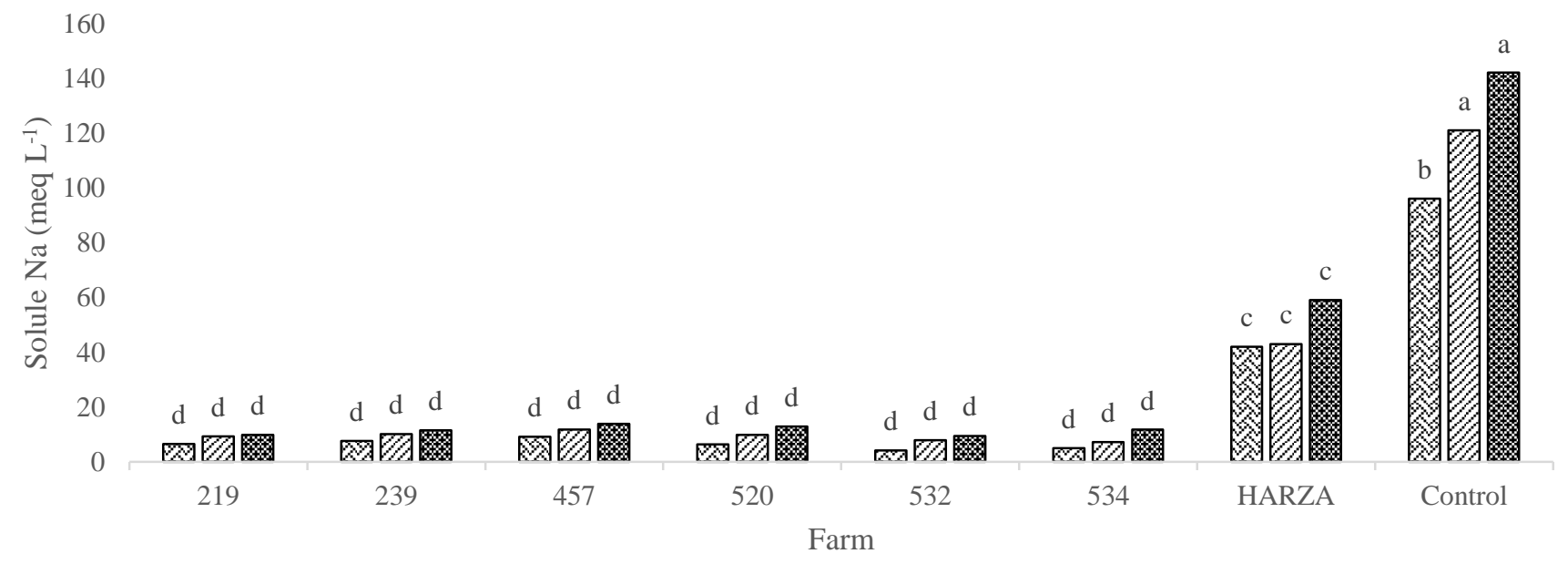

Figure 5- Comparison of means of soluble sodium in soils under sugarcane cultivation with those of control and HARZA report 
Table 1- Analysis of variance of soil properties of the soils under long-term sugarcane cultivation

\begin{tabular}{|c|c|c|c|c|c|c|c|c|c|c|}
\hline $\begin{array}{l}\text { Sources of } \\
\text { changes }\end{array}$ & $\begin{array}{c}\text { Degree } \\
\text { of } \\
\text { freedom }\end{array}$ & SOM & $\begin{array}{c}\text { Available } \\
\text { Phosphorous }\end{array}$ & $\mathrm{CaCO} 3$ & Gypsum & $S B D$ & $\begin{array}{l}\text { Soluble } \\
\text { sodium }\end{array}$ & $\begin{array}{c}\text { Absorbable } \\
\text { potassium }\end{array}$ & $p H$ & $E C$ \\
\hline Block & 2 & $0.03^{* *}$ & $2.22^{* *}$ & $77.38^{\mathrm{ns}}$ & $0.01^{* *}$ & $0.14^{* *}$ & $994.58^{\mathrm{ns}}$ & $1191.45^{* *}$ & $3.82^{* *}$ & $0.69^{* *}$ \\
\hline Farm & 7 & $0.15^{* *}$ & $17.50^{* *}$ & $6.50^{* *}$ & $3.07^{* *}$ & $0.10^{* *}$ & $22408.8^{* *}$ & $25719.9^{* * *}$ & $0.12^{* *}$ & $374.94^{* * *}$ \\
\hline Sampling depth & 2 & $2.05^{* *}$ & $203.75^{* *}$ & $43.61^{* *}$ & $0.53^{* *}$ & $0.25^{* *}$ & $179.35^{\mathrm{ns}}$ & $6414.78^{* *}$ & $0.03^{* *}$ & $3.89^{* *}$ \\
\hline Farm * Depth & 14 & $0.08^{* *}$ & $8.18^{* *}$ & $5.31^{* *}$ & $0.21^{* *}$ & $0.01^{* *}$ & $190.26^{\mathrm{ns}}$ & $5202.01^{* *}$ & $0.01^{\text {** }}$ & $0.64^{* *}$ \\
\hline Total error & 71 & 0.0007 & 0.02 & 0.59 & 0.0008 & 0.00008 & 2.21 & 9.62 & 0.001 & 0.09 \\
\hline CV (percentage) & - & 4.21 & 2.50 & 1.75 & 4.99 & 0.57 & 6.78 & 2.20 & 0.41 & 9.11 \\
\hline
\end{tabular}

\subsection{Soil exchangeable potassium}

The changes in land use from pristine lands to sugarcane-cultivated lands result in a significant decrease in available potassium in all three depths, especially at depth 0-30 cm (Figure 6). As a result, the average available potassium in the surface soil was decreased from $185 \mathrm{mg} \mathrm{kg}^{-1}$ in the control soil to $100 \mathrm{mg} \mathrm{kg}^{-1}$ in the cultivated fields. This reduction is more severe at depth 0 $30 \mathrm{~cm}$ as compared with lower depths. As can be seen, the amount of potassium at 0-30 cm depth in HARZA report is greater than that of the control farm, which is significant as well, and seems to be due to the application of potassium fertilizer at the beginning of sugarcane cultivation. However, because of the continuous cropping of this plant and excessive discharge of this element from 0-30 $\mathrm{cm}$ depth of soil, it gradually decreased in amount compared to the soil of the control and HARZA report (Figure 6). The reason of this observation would be attributed to potassium uptake by sugarcane and the high demand for potassium in this plant. In general, it can be said that the reduction of available potassium in soils in sugarcane-cultivated lands is the excessive depletion of potassium from the soil, due to the absorption of this element by sugarcane as well as the leaching of this nutrient caused by heavy irrigation. The results of this study are consistent with the findings of Bostani and Savaghebi (2011), which reported a significant reduction in potassium content in soils under long-term cultivation of sugarcane. Van Antwerpen et al. (2007) also stated that uncultivated land had higher values of exchangeable K than cultivated land. According to these results, it can be concluded that long-term sugarcane cultivation without using potassium fertilizer causes excessive depletion of this element and leads to decreasing potassium content of the plant and thus reducing plant yield.

因0-30 \30-60 田60-90

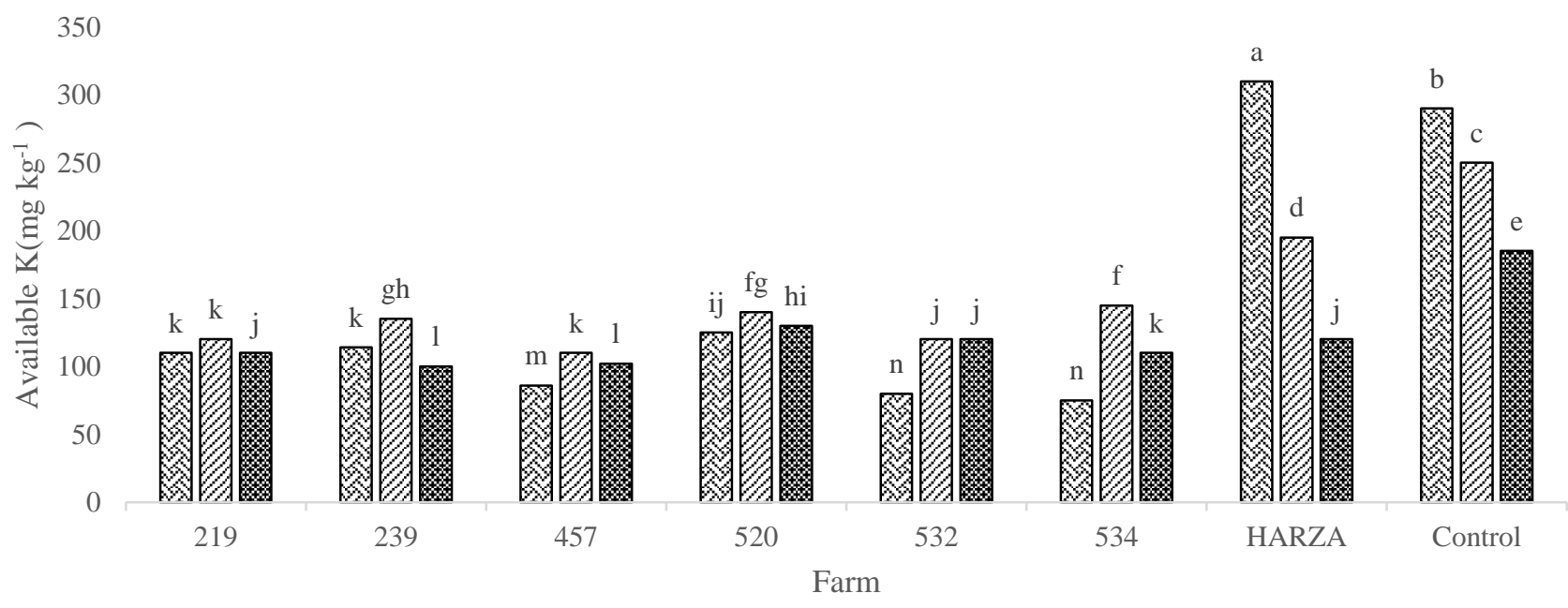

Figure 6- Comparison of the average absorbable potassium in the soil under sugarcane cultivation with the control and HARZA report

\subsection{Soil available phosphorous}

The soil available phosphorus content at $0-30 \mathrm{~cm}$ depth of sugarcane fields imply a statistically difference from that of control farm (Figure 7). The average amount of available phosphorus at 0-30 cm depth increased from $6 \mathrm{mg} \mathrm{kg}^{-1}$ in the HARZA report to $15.6 \mathrm{mg} \mathrm{kg}^{-1}$ in sugarcane cultivated fields. Meanwhile, there is no significant difference between the mean of available phosphorus in the farms under cultivation and the soil of the control farm and HARZA at the depth of 30-60 cm. The reason for the increased amount of phosphorus in soils under sugarcane cultivation is the addition of phosphorus fertilizers (triple super phosphate and ammonium phosphate) in sugarcane cultivation farms. However, the difference between the amounts of available phosphorus in different farms under sugarcane cultivation can be attributed to the difference management and applied amount of phosphate fertilizers in the farms (Figure 7). The increased amount of phosphorus in sugarcane cultivated fields in comparison 
with the soil of the control and HARZA report can be attributed to the ability of phosphorus to form colloidal bonds with the soil grains and, therefore, no leaching of the element even in heavy irrigation operations conducted in such farms. This process leads to the gradual deposition of phosphorous in the soil and, consequently, a gradual increase of the element in the soil. Conversion of natural ecosystem to vegetable lands increased phosphorous proportion in the soils (Ahmad et al. 2017). Investigation the fate of phosphorous in Everglades agriculture soils implied that soil total phosphorous of sugarcane soil was higher than uncultivated soil as result of years of historical phosphorous fertilizer (Wright et al. 2012).

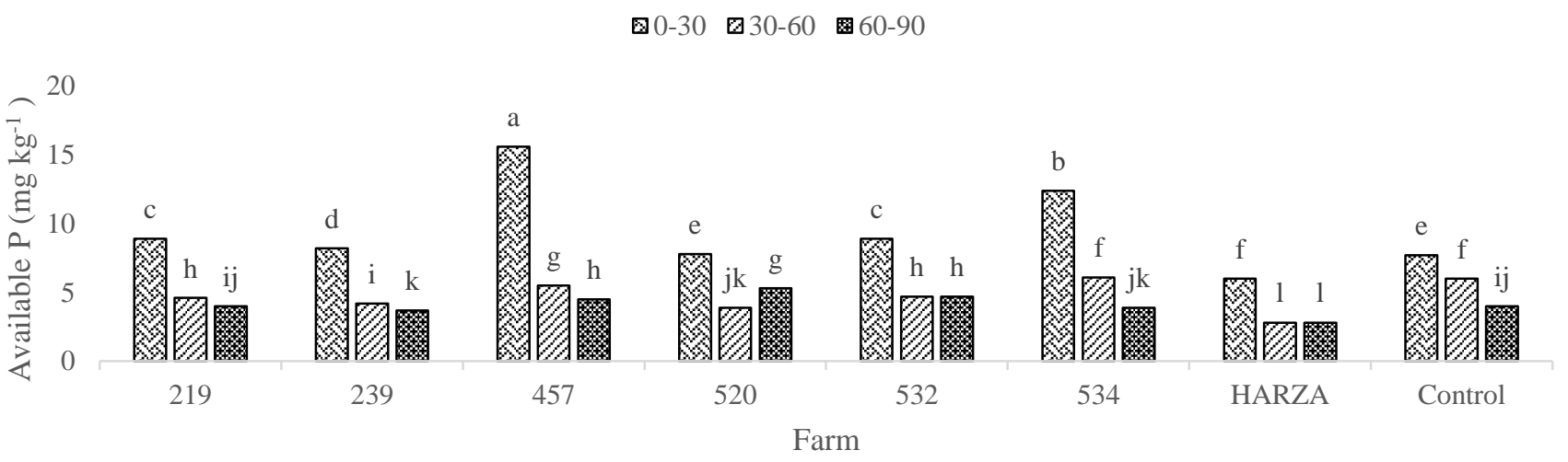

Figure 7- Comparison of means of available phosphorus in soils under sugarcane cultivation with those of control and HARZA report

\subsection{Soil bulk density}

The results of comparing Duncan's means showed that continuous sugarcane cultivation led to an increase in soil bulk density, especially at the depth of 30-60 cm. By comparing the soil bulk density of control farm $\left(1.41 \mathrm{~g} \mathrm{~cm}^{-3}\right)$ and the soil of HARZA $\left(1.32 \mathrm{~g} \mathrm{~cm}^{-3}\right)$ with the soil from continuously cultivated fields, it was observed that, in the early years, the texture of soil has turned porous and lighter, due to soil tillage. However, due to heavy tillage and transportation of tillage equipment in the field, the texture of soil has gradually become heavier and denser, which not only prevented the development of the root, but has also led to retaining water in the plant root area, resulting in reduced yield. The results are consistent with the findings of Moradi et al. (2014) as to increasing soil bulk density values, due to heavy tillage in Haft-Tapeh Agro-industry Unit.

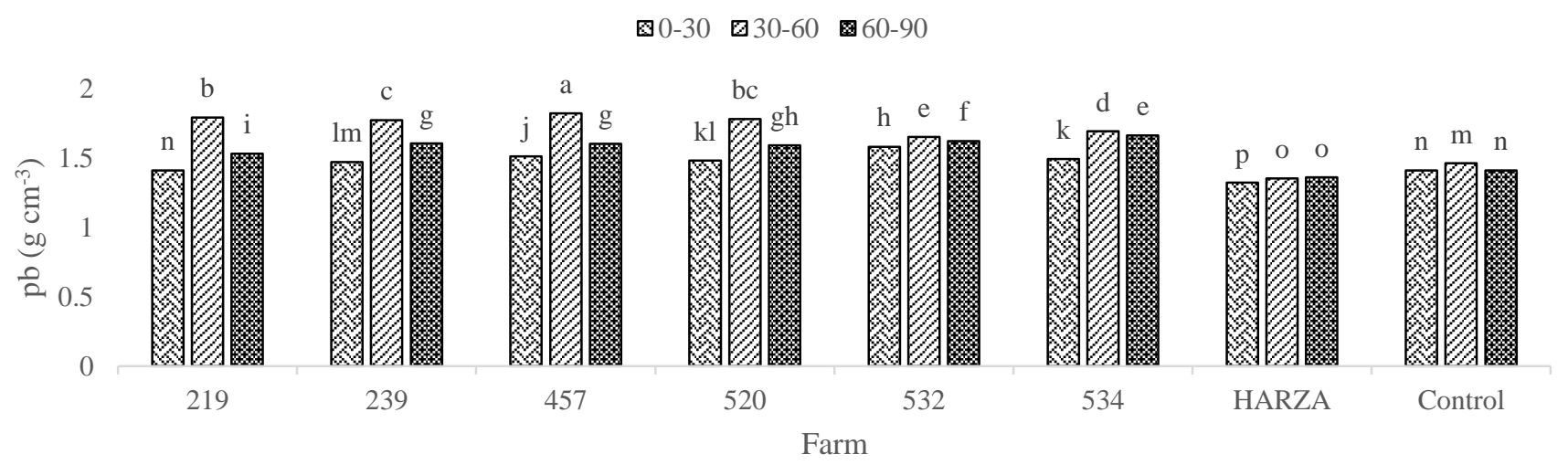

Figure 8- Comparison of means of soil bulk density in sugarcane farms with those of the control and HARZA report

\section{Conclusions}

The obtained finding revealed a direct relationship between changing land use and long-term sugarcane cultivation and physical and chemical properties of soil. Land use change, abundant irrigation and leaching, and long-term sugarcane cultivation had the ability of decreasing the salinity constraints and soluble sodium in pristine soils and increasing the organic matter content of the soil. These changes are greater in the surface depths of the soil than the deeper ones. While the amount of available phosphorus increased, due to long-term cultivation and fertilization, the available potassium greatly decreased in the farms under sugarcane cultivation. Since sugarcane consumes high amounts of potassium, the reduction of available potassium can be a limiting factor in its growth and yield. Also, the findings of this study showed that the heavy tillage operations by tillage equipment, caused a 
gradual increase in soil bulk density in the depth of $30-60 \mathrm{~cm}$ in the farms, leading to an increase in the density of soil in this horizon. Consequently, the increased soil bulk density prevents the development of sugarcane root and, by creating damp conditions, prevents the availability of enough oxygen for the plant, resulting in the inability of the plant to absorb nitrogen and other nutrients from the soil and, therefore, reduced yield of the plant. In general, the results of this study showed that in order to prevent probable negative consequences and the depletion of nutrients in soil, especially potassium, and to increase soil bulk density, it is necessary to periodically evaluate the changes in the characteristics of sugarcane planted soils. The obtained results will provide a guidance to finding a suitable management techniques for maintaining soil quality.

\section{Acknowledgements}

The authors express their sincere thanks to Islamic Azad University of Ahvaz, Science and Research Branch for their academic and financial supports. Furthermore, we are thankful of Dr. Mahmoud Validy, Department of English literature, Shahid Chamran University of Ahvaz, Iran, for improving the language of manuscript.

\section{References}

Ahmad E H, Demisie W \& Zhang M (2017). Effects of land use on concentrations and chemical forms of phosphorus in different-size aggregates. Eurasian soil science 50(12): 1435-1443 DOI: 10.1134/S1064229317120110

Amerikhah H, Chorom M, Landi A \& Jafari S (2010). Application of DNDC model for estimating greenhouse carbon gases emission as effect of changing land use in south of Ahwaz. J. Agric. Engin. Crop, Soil Agric. Machin 33(1): 1-14

Barzegar A, Mahmoudi SH, Hamedi F \& ABD A F (2005). Long term sugarcane cultivation effects on physical properties of fine textured soils. Journal of Agricultural Science and Technology 7: 59-68

Blanco-Canqui H \& Lal R (2007). Soil and crop response to harvesting corn residues for biofuel production. Geoderma 141(3-4): 355-362 DOI: $10.1016 /$ j.geoderma.2007.06.012

Bostani A \& Savaghebi G H (2011). Study of potassium fixation capacity in some undercultivation sugarcane soils in Khuzestan. Journal of Water and Soil (Agricultural Sciences and Technology) 25: 5. 982-993 (In Persian)

Bünemann E K, Bongiorno G, Bai Z, Creamer R E, De Deyn G, de Goede R \& Pulleman M (2018). Soil quality-A critical review. Soil Biology and Biochemistry 120: 105-125 DOI:10.1016/j.soilbio.2018.01.030

Jafari S, Golchin A \& Toolabifard A (2016). Effect of land use changes on physical fractionation properties of organic matter, clay dispersion and aggregate stability in some Khuzestan soils province. Iranian Journal of Soil and Water Research 47: 3. 593-603 (In Persian) DOI:10.22059/ijswr.2016.59329

Landi A, Pourkeihan S, Chorom M, Hojati S \& Jafari S (2018). Study of the effects of land use change and construction of sugarcane fields on physicochemical, mineralogical and micromorphological characteristics of soil in southern Khuzestan province. Journal of soil management and sustainable production 8: 2. 53-62 (In Persian) DOI: 10.22069/ejsms.2017.10968.1639

Moradi F, Khalili Moghadam B, Jafari S \& Ghorbani Dashtaki S (2014). Long-Term Effects of Mechanized Cultivation on Some Soil Physical Properties in Some Khouzestan Sugarcane Agro-Industries. Journal of Water and Soil (Agricultural Sciences and Technology) 27(6): 11531165

Naranjo de la F J, Salgado-Garci'a S, Lagunes-Espinoza L C, Carrillo-Avila E \& Plama-Lopez D J (2006). Change in the properties of a Mexican Fluvisol fllowing 30 years of sugarcane cultivation. Soil \& Tillage Research (88): 160-167 DOI:10.1016/j.still.2005.05.006

Rezapour S, Taghipour A \& Samadi A (2013). Modifications in selected soil attributes as influenced by long-term continuous cropping in a calcareous semiarid environment. Natural Hazards 69: 3. 1951-1966 DOI: 10.1007/s11069-013-0786-8

Silva A J N, Ribeiro M R, Carvalho F G, Silva V N \& Silva L E S F. (2007). Impact of sugarcane cultivation on soil carbon fractions, consistence limits and aggregate stability of Yellow Latosol in Northeast Brazil. Soil and Tillage Research 94: 420-424 DOI:10.1016/j.still.2006.09.002

Staff S (2014). Keys to soil taxonomy. Washington (DC): United States Department of Agriculture, Natural Resources Conservation Service

Van Antwerpen R, Lyne P W, Meyer E, \& Brouwers M (2007). Changes in soil physical parameters of a virgin soil due to compaction by commercial sugarcane haulage vehicles. InProc. Int. Soc. Sug. Cane Technol (Vol. 26, pp. 470-475)

Wright A L, Hanlon E A \& McCray J M (2012). Fate of phosphorus in everglades agricultural soils after fertilizer application (No. DOEHENDRYFLA-00303-219; EDIS-SL290). Intelligentsia International, LaBelle, FL (United States) http://edis.ifas.ufl.edu 